Voix et Images

volXetimages

\title{
Index du volume XXIII
}

Volume 24, numéro 1 (70), automne 1998

Yves Préfontaine

URI : https://id.erudit.org/iderudit/201422ar

DOI : https://doi.org/10.7202/201422ar

Aller au sommaire du numéro

Éditeur(s)

Université du Québec à Montréal

ISSN

0318-9201 (imprimé)

1705-933X (numérique)

Découvrir la revue

Citer ce document

(1998). Index du volume XXIII. Voix et Images, 24(1), 227-228.

https://doi.org/10.7202/201422ar d'utilisation que vous pouvez consulter en ligne.

https://apropos.erudit.org/fr/usagers/politique-dutilisation/ 


\section{Index du volume XXIII}

AUDET, René, "Le récit, émergence d'une pratique:le volet institutionnel", 3, p. 439460.

BERTHIAUME, Pierre, "Paul Lejeune ou le missionnaire possédé", 3, p. 529-543.

BIRON, Michel, "L'enfant, la mère », 1, p. 177-181 ; "Deconstructing Marcel », 3, p. 593597.

BOURQUE, Dominique, "Héloïse ou La voix du silence dans Une saison dans la vie d'Emmanuel", 2, p. 329-345.

BROCHU, André, "Quatre échos du divin moi ", 3, p. 603-606.

CHAMBERLAND, Paul, "Se confier à la source", 2, p. 406-409.

CHASSAY, Jean-François, "Vies minuscules", 1, p.173-177; "Ruser avec la mort", 3, p. $597-602$.

CLOUTIER, Yvan, "Sartre à Montréal en 1946: une censure en crise ", 2, p. 266-280.

DAUNAIS, Isabelle, "Histoires de continents", 2, p. 403-406.

DUPRÉ, Louise, "Avant-propos", 1, p. 5-6; "Avant-propos", 2, p. 217-218; "Avantpropos", 3, p. 433-434.

FORTIER, Frances, "Présentation", 3, p. 437-438; "Le récit, émergence d'une pratique: le volet institutionnel ", 3, p. 439-460.

GAUDET, Gérald, "Aimer et raconter dans La fête du désir", 1, p. 39-51.

GIGUÈRE, Richard, " "Vous vous rendez compte, n'est-ce pas, qu'une moitié ou plus des chefs-d'œuvres [sic] de la littérature française sont interdits aux catholiques obéissants?": un témoignage majeur de Louis Dantin. Présentation ", 2, p. 224-225; " "Ces restes d'Inquisition..." Littérature, édition et censure dans les correspondances d'écrivains de l'entre-deux-guerres au Québec", 2, p. 248-265.

GREEN, Mary Jean, "L'itinéraire d'une écriture au féminin: une lecture féministe de Madeleine Ouellette-Michalska ", 1, p. 84-99.

GUILLEMETTE, Lucie, "L'inscription du savoir historique dans l'énoncé au féminin: la genèse de l'Amérique dans La maison Trestler", 1, p. 52-64.

HÉBERT, Pierre, "Présentation", 2, p. 221-223; " Où est l'univers concentrationnaire?": Le Devoir et les paradigmes de la censure (1920-1960)", 2, p. 229-247; "Entrevue avec $M$. Fulgence Charpentier", 2, p. 317-325.

KÈGLE, Christiane, "L'imaginaire symbolisé dans trois récits contemporains", 3, p. 481500.

LAFRANCE, Geneviève, "Saint-Denys Garneau et le dọ épistolaire. La lettre du 30 décembre 1932", 1, p. 119-134.

LAMONTAGNE, André, "Lectures d'ailleurs', 1, p. 188-194; "Écrire l'Amérique ", 3, p. 612-617. 
LAROCHELLE, Corinne, "Lire l'image: Le bruit des choses vivantes d'Élise Turcotte", 3, p. 544-557.

LEMAIRE, Michel, "Le fleuve et la mort ", 3, p. 607-612.

L'HÉRAULT, Pierre, "Le je incertain: fragmentations et dédoublements", 3, p. 501-514.

LUNEAU, Marie-Pier, "Présentation de l'entrevue avec Fulgence Charpentier ", 2, p. 314316.

MAJOR, Robert, "Greimas et Thériault", 1, p. 169-173; "Les voies de la critique ", 2, p. 385-393; "L'invitation au voyage", 3, p. 583-590.

MERCIER, Andrée, "Présentation", 3, p. 437-438; "Poétique du récit contemporain: négation du genre ou émergence d'un sous-genre? », 3, p. 461-480.

MOCQUAIS, Pierre-Yves, "Lire VLB", 2, p. 393-399.

MONTREUIL, Sophie, "Petite histoire de la nouvelle "Un jardin au bout du monde" de Gabrielle Roy", 2, p. 360-381.

OUELLETTE-MICHALSKA, Madeleine, "La passagère (extrait)", 1, p. 25.

PAQUIN, Jacques, "La poésie comme une passion tranquille", 2, p. 409-413.

PATERSON, Janet M., "Présentation", 1, p. 9-10; "L'écriture du désir. Entretien avec Madeleine Ouellette-Michalska ", 1, p. 11-24.

POIRIER, Maryse, "L'art de l'esquive: quelques astuces du personnage en quête de soi ", 3, p. 515-525.

PRZYCHODZEŃ, Janusz, "La dialectique du paradoxe et du paroxysme dans Dévadé de Réjean Ducharme ", 2, p. 346-359.

RANDALL, Marilyn, "Histoire, roman et texte national: comment lire L'été de l'île de Grâce", 1, p. 65-83; "L'homme et l'œuvre: biolectographie d'Hubert Aquin", 3, p. 558-579.

ROBERT, Lucie, "Minces propos ", 1, p. 181-188.

ROBERTS, Paula, "Bibliographie de Madeleine Ouellette-Michalska", 1, p. 100-116.

ROBINSON, Christine, "La route d'Altamont de Gabrielle Roy, épave de La saga d'Êveline? „, 1, p. 135-146.

SAINT-MARTIN, Lori, "Regards sur le Québec", 2, p. 399-402.

SALAÜN, Élise, "Érotisme littéraire et censure : la révolution cachée"; 2, p. 297-313.

SEYFRID, Brigitte, "L'éloquence ferronienne. Étude rhétorique des discours et des sermons dans Le ciel de Québec", 1, p. 147-165.

SIMON, Sherry, "Des langues qui résonnent", 3 , p. 590-592.

VIENS, Nathalie, "L'humanisme intégral comme doctrine censoriale. La revue Lectures des éditions Fides (1946-1951)", 2, p. 281-296.

VIGNEAULT, Robert, "Madeleine Ouellette-Michalska, essayiste: une écriture qui se cherche", 1, p. 26-38. 